From several in vitro and in vivo studies involvement of somatostatin (SMS) in intestinal inflammation emerge. Acute colitis induced in rats is attenuated by the long-acting SMS analogue octreotide. We studied the potential beneficial effect of SMS on non-acute experimental colitis. BALB/c mice received either saline, SMS-14 (36 or $120 \mu \mathrm{g}$ daily) or octreotide (3 $\mu \mathrm{g}$ daily) subcutaneously delivered by implant osmotic pumps. A non-acute colitis was induced by administration of dextran sodium sulphate (DSS) $10 \%$ in drinking water during 7 days. DSS evoked a mild, superficial pancolitis, most characterized by mucosal ulceration and submucosal influx of neutrophils. Neither SMS-14 nor octreotide reduced mucosal in flam $m$ a tory score or macroscopical disease activity, although reduction of in testinal levels of in terleukin $1 \beta$ (IL-1 $\beta$ ), IL-6 and IL-10 during DSS was augmented both by SMS and octreotide. A slight increase of neutrophil influx was seen during SMS administration in animals not exposed to DSS. In conclusion, SMS or its long-acting analogue did not reduce intestinal inflammation in non-acute DSS-induced colitis. According to the cytokine profile observed, SMS-14 and octreotide further diminished the reduction of intestinal macrophage and Th 2 lymphocyte activity.

Key words: intestinal inflammation, somatostatin, neuropeptide, experimental colitis, dextran sulphate

\section{Somatostatin does not attenuate intestinal injury in dextran sodium sulphate-induced subacute colitis}

\author{
J. D. van Bergeijk, ${ }^{1,3, C A}$ M. E. van Meeteren², \\ C. J. A. M. Tak', A. P. M. van Dijk', \\ M. A. C. Meijssen', J. H. P. Wilson ${ }^{1}$ and F. J. Zijlstra ${ }^{2}$
}

${ }^{1}$ Department of Gastroenterology/Internal Medicine, University Hospital Rotterdam, and ${ }^{2}$ Department of Pharmacology, Erasmus University Rotterdam, The Netherlands ${ }^{3}$ Present address: c/o Hospital 'Gelderse Vallei', PO Box 9056, 6700 GR Wageningen, The Netherlands

$\mathrm{CA}, 3$ Corresponding Author

Tel: (+31) 317473111

Fax: (+31) 317473139

\section{Introduction}

Neuropeptides play key roles in intestinal inflammation. ${ }^{1}$ One of the most considerable inhibitory neuropeptides is somatostatin (SMS), which has dosedependent inhibitory effects on lymphocyte proliferation and cytokine production, immunoglobulin synthesis and macrophage function. ${ }^{2}$ It stimulates development and immunologic activity of intestinal granulomas in murine Schistosomiasis mansoni infection. ${ }^{3,4}$ Mucosal depletion of SMS is observed in inflammatory bowel disease. ${ }^{5-8}$ In contrast, blood SMS levels in active IBD are elevated, so a defensive role in intestinal mucosal injury is suggested. ${ }^{9,10}$ Octreotide, a long-acting SMS analogue, is able to reduce epithelial damage in an animal model of acute experimental colitis. ${ }^{11}$ No data on the effects of somatostatin or its analogues on chronic colitis are available.

When laboratory animals are exposed to dextran sulphate sodium (DSS) in their drinking water, a mild colitis develops. Although one of the characteristic events evoked by DSS is an enhanced T-cell response, ${ }^{12}$ colitis is induced irrespective the presence of lymphocytes. ${ }^{13,14}$ DSS-induced colitis is an important, reproducible and economic model of intestinal inflammation, mimicking certain aspects of inflammatory bowel disease. ${ }^{15}$ In the acute phase it is characterized by a predominantly left-sided, acute colitis, which is not contiguous. ${ }^{16,17}$ Already 1 week after starting DSS exposure, a mild subacute colitis has developed, which responds to several immunemodulating agents. ${ }^{18-20}$ Certainly pro-inflammatory neuropeptides (substance $\mathrm{P}$, neuropeptide $\mathrm{Y}$ ) are involved in DSS-induced colitis. ${ }^{21}$ The relevance of inhibitory neuropeptides like SMS in this model has not been studied before.

We aimed to determine the role of SMS in DSSinduced subacute intestinal inflammation in mice, focused on intestinal leukocyte infiltration and cytokine content. Pro-as well as anti-inflammatory cytokines were concerned in this study. Departing from above mentioned immune inhibitory effects, we anticipated a beneficial effect of SMS administration on intestinal mucosal damage.

\section{Methods}

\section{Experimental protocol}

All experiments were approved by the Laboratory Animal Ethics Committee of the Erasmus University. 
Forty adolescent female BALB/c mice $(20-22 \mathrm{~g})$ were randomly allocated to eight groups (A to $\mathrm{H}$ ). All mice received subcutaneously inserted osmotic pumps (Alzet, Germany) which were placed in the upper region of the back under ether anaesthetic surgery. Osmotic pumps were filled with saline, SMS-14 or octreotide. Groups A and B received normal saline. The pumps in groups $\mathrm{C}, \mathrm{D}, \mathrm{E}$ and $\mathrm{F}$ were filled with SMS acetate, containing SMS-14 (Somatofalk ${ }^{\circledR}$, Tramedico, Weesp, The Netherlands). These pumps continuously released subcutaneous SMS-14 during 7 days (groups $\mathrm{C}$ and D $36 \mu \mathrm{g}$, and groups E and F $120 \mu \mathrm{g}$ daily). Groups $\mathrm{G}$ and $\mathrm{H}$ received octreotide $3 \mu \mathrm{g}$ daily (Sandostatine ${ }^{\circledR}$, Novartis, Basle, Switzerland). Immediately thereafter animals in groups B, D, F and Hwere exposed to DSS $10 \%$ in their drinking water during 7 days. Control groups were allowed to drink normal water. All animals had free access to drinking water and normal food. Subsequent to an overnight fasting animals were killed by cervical dislocation 7 days after implantation of osmotic pumps. All operations and sacrificing took place between 09.00 and $11.00 \mathrm{~h}$.

\section{Macroscopy}

Severity of inflammation was documented macroscopically, considering changes of bodyweight and general appearance (hair, liveliness). Stools and rectal bleeding, and colour, distension and serosal appearance of the colon directly after opening of the abdomen were scored. A maximum macroscopic score of 10 points was allocated, according to the following: as adolescent mice gain at least 5\% bodyweight per week, change of bodyweight of more than $5 \%$ was scored $0,0-5 \%$ gain $=1$, loss of bodyweight $=2$. Hair was normal (0) or dull (1); mice were lively (0) or apathetic (1). Stools were normal (0), semiliquid (1) or liquid (2). Rectal bleeding was given 1 point. Colon colour was normal (0) or red (1); distention was absent (0) or remarkable (1). The serosal aspect was normal (0) or thickened (1).

\section{Intestinal specimens}

Immediately after sacrificing, the colon and small bowel were taken out. Faecal contents were carefully removed. Fragments of terminal ileum, and proximal, middle and distal colon were cut to a standardized length alongside a measuring rod. Specimens for histology were placed immediately in formaldehyde. For cytokine analysis fragments were kept in Krebs's buffer after weighing.

\section{Histological examination}

Histological sections from ileum, and proximal, middle and distal parts of the colon were stained (haematoxylin and eosin) and scored to extent of inflammation $(0$ =none, $1=$ mild, $2=$ moderate, $3=$ severe $)$, damage $(0=$ none, $1=$ superficial, $2=$ involving m.mucosae, $3=$ transmural), and regeneration (3=none, 2 =focal, 1 =multifocal, $0=$ complete). ${ }^{13}$ Assessments were made by a blinded committee. Scores from proximal, middle and distal colon parts were added to obtain a total histology score per animal.

\section{Cytokine analysis}

Tissue specimens were fragmented during $10 \mathrm{~s}$ in Krebs's buffer (Ultra-Turrax, Polyton, Switzerland)

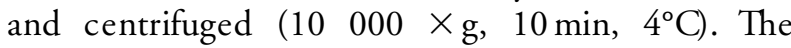
supernatant was stored at $-80^{\circ} \mathrm{C}$ for cytokine assay. Levels of interleukin-1 beta (IL-1 $\beta$ ), IL-6, IL-10 and interferon gamma (IFN $\gamma$ ) were measured by ELISA kits for assay of mouse cytokines (Biosource, Belgium). Levels are expressed as cytokine per tissue weight $(\mathrm{pg} / \mathrm{mg})$.

\section{Analysis}

Descriptive analysis was performed concerning macroscopic changes. Cytokine values were expressed as mean \pm standard error. Results were analysed using a Wilcoxon two-sided rank sum test for small samples (macroscopy/microscopy) or an unpaired $t$-test (cytokine levels). $P$-values under 0.05 were considered statistically significant.

\section{Results}

\section{Macroscopy}

All DSS-treated animals developed colitis and revealed a significant higher macroscopy score than controls (6.2 \pm 1.2 vs. $0.4 \pm 0.2, P<0.01)$. Macroscopy scores in groups $\mathrm{C}, \mathrm{E}$ and $\mathrm{G}$ ('non-inflamed') did not differ from controls $(0.8 \pm 0.6,0.8 \pm 0.4$, and $0 \pm 0$, NS compared with A). Neither SMS nor octreotide significantly affected macroscopy scores in the colitis groups $\mathrm{D}, \mathrm{F}$ and $\mathrm{H}(4.8 \pm 1.6,5.8 \pm 0.9$ and $7.0 \pm 1.4$, NS compared with B).

\section{Histology}

No inflammation was seen in the ileal specimens. A mild pancolitis was induced by DSS. Mucosal infiltration of polymorphonuclear neutrophils (PMN) was the most remarkable finding. Histology scores from proximal and distal colon parts in animals exposed to DSS did not differ. Scores in groups B $(7.2 \pm 0.5)$, D $(8.8 \pm 0.8), \mathrm{F}(6.8 \pm 0.6)$ and $\mathrm{H}(8.6 \pm 1.2)$ were significant higher than group A $(3.0 \pm 0.3, P \leq 0.05)$. Scores from group E $(3.6 \pm 1.7)$ and $G(4.2 \pm 0.8)$ were higher than controls, but these differences were not statistically different. In group $\mathrm{C}$ inflammatory 
score was high $(5.2 \pm 0.8)$, merely due to PMN infiltration. Mucosal damage was not obviously present in group $\mathrm{C}$ as the total microscopy score minus the score for $\mathrm{PMN}$ infiltration was $1.6 \pm 0.5$ points for group $\mathrm{C}$, compared with $0.8 \pm 0.2$ points for controls $(P>0.05)$.

\section{Cytokines}

IFN $\gamma$ was barely detectable in most samples $(\leq 0.4 \mathrm{pg} /$ $\mathrm{mg})$. Statistical analysis was not possible, due to abnormal distribution of data.

IL-1 $\beta$ levels in groups B, C, D, F, G and H $(15.5 \pm$ $3.3,19.3 \pm 3.5,19.2 \pm 7.3,5.9 \pm 1.7,10.6 \pm 1.8$ and $10.1 \pm 5.4 \mathrm{pg} / \mathrm{mg}$ ) were significantly lower than in group A $(27.4 \pm 5.3 \mathrm{pg} / \mathrm{mg}, P \leq 0.05)$. Mucosal IL-1 $\beta$ concentration in group E $(27.5 \pm 7.9 \mathrm{pg} / \mathrm{mg})$ was not different from A (Fig. 1a). In $F$ the IL-1 $\beta$ levels were significantly lower than in $\mathrm{B}(P<0.001)$.

IL-6 levels in groups B, D, F, G and $\mathrm{H}(21.3 \pm 5.1$, $21.4 \pm 5.2,14.1 \pm 4.1,27.4 \pm 2.8$ and $12.1 \pm 5.9 \mathrm{pg} /$ $\mathrm{mg})$ were lower than in group A $(54.5 \pm 11.2 \mathrm{pg} / \mathrm{mg}$, $P<0.01$, Fig. 1b). IL-6 levels in C $(45.6 \pm 5.5)$ and E $(51.7 \pm 6.8 \mathrm{pg} / \mathrm{mg})$ did not differ from $\mathrm{A}(P>0.4) . \mathrm{D}, \mathrm{F}$, $\mathrm{G}$ and $\mathrm{H}$ did not significantly differ from $\mathrm{B}(P=$ $0.2)$.

IL-10 concentration (Fig. 1c) in group B $(9.7 \pm$ $3.8 \mathrm{pg} / \mathrm{mg})$ was lower than in A $(20.9 \pm 6.2 \mathrm{pg} / \mathrm{mg})$, but statistical significance was not reached $(P=0.17)$. IL-10 levels in D, F and $\mathrm{H}(6.7 \pm 1.7,6.3 \pm 2.4$ and 6.1 $\pm 0.7 \mathrm{pg} / \mathrm{mg})$ were lower than in controls $(P<0.05)$. In groups $C(16.2 \pm 3.8 \mathrm{pg} / \mathrm{mg}), \mathrm{E}(22.8 \pm 6.9 \mathrm{pg} / \mathrm{mg})$ and G (14.9 $\pm 4.9 \mathrm{pg} / \mathrm{mg})$ IL-10 levels did not significantly differ from controls.

\section{Discussion}

In our study DSS induced a mild, superficial colitis, both left and right-sided, rarely involving layers beyond the muscularis mucosae. The most characterizing finding was mucosal infiltration by neutrophils (PMN). Neither SMS nor octreotide did attenuate DSSinduced mucosal inflammation. Low dose SMS and octreotide-treated animals that were exposed to normal drinking water showed a marked mucosal infiltration by PMN, without mucosal damage. In these groups mucosal IL-1 $\beta$ content was reduced, perhaps reflecting a negative feedback by increased PMN influx. This increased PMN influx was limited to the colon, as all ileal specimens were normal. As neutrophil migration into the intestinal mucosa is the prominent occurring phenomenon in DSS-induced colitis, the meaning of this infiltration without causing mucosal damage is unclear. However, in vitro leukocyte migration is stimulated by SMS, ${ }^{22,23}$ by an as yet undefined mechanism.
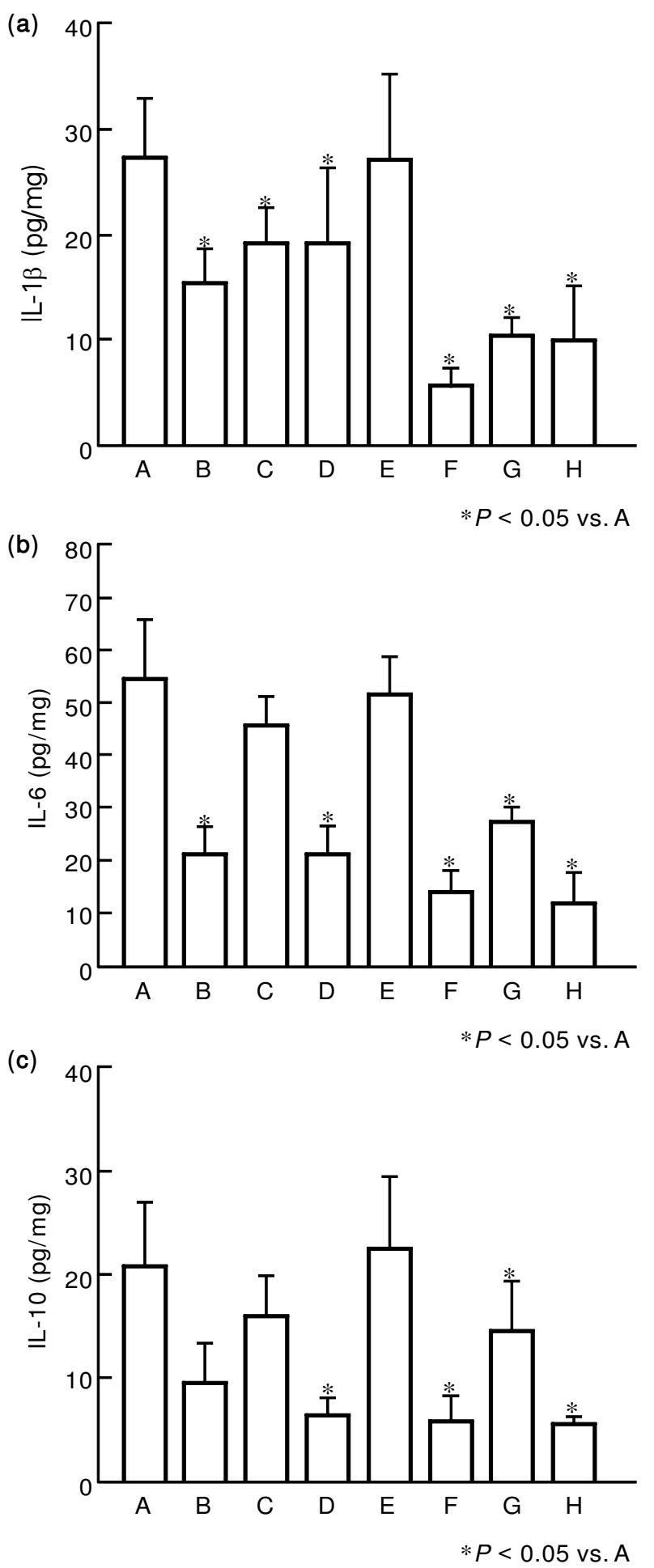

FIG. 1. Cytokine levels in colon mucosa in $\mathrm{pg} / \mathrm{mg}$ tissue weight. $A=$ saline; $B=$ saline/DSS; $C=S M S 36$ ug; $D=S M S$ 36 ug/DSS; $E=$ SMS 120 ug; $F=$ SMS 120 ug/DSS; $G=$ OCT 3ug; $\mathrm{H}=3 \mathrm{ug} / \mathrm{DSS}$.

Several beneficial effects of SMS or SMS analogues on intestinal inflammation of various aetiologies have been demonstrated. ${ }^{24-27}$ In an acute model of experimental colitis (acetic acid) octreotide in high-dose attenuated mucosal inflammation and local cytokine 
and eicosanoid production. ${ }^{11}$ A most distinct effect was seen when octreotide was administered the day before induction of acute colitis. As no follow-up studies on rate of mucosal regeneration were performed, no data are known on the probable beneficial effects of octreotide in the post-toxic period of acetic acid. These results do not find support from our results, which might be due to the use of different models and experimental animals. Acetic-acidinduced colitis is an acute toxic model in which nonspecific inflammation prevails. ${ }^{15}$ DSS-induced murine colitis is a model of acute as well as non-acute colitis. ${ }^{13,16,17}$ This model has been found suitable for studying involvement of mediators of mucosal inflammation and evaluation of anti-inflammatory treatment. ${ }^{18,20,28}$ DSS most likely acts as a direct mucosal toxin, as inflammation occurs irrespective of the presence of lymphocytes or other mucosal immunocytes. $^{13,14,29}$ However, in the non-acute DSS-induced colitis intestinal macrophages, neutrophils and lymphocytes are affected. ${ }^{13,19,30}$ Corticosteroids, cyclosporin A or anti-neutrophil serum attenuate DSSevoked inflammatory changes. ${ }^{18-20}$

In chronic DSS-induced colitis an enhanced Th1 response is observed, which is accompanied by increased intestinal $\mathrm{IFN}_{\gamma}$ content. ${ }^{31}$ However, we were not able to detect $\mathrm{IFN}_{\gamma}$ in our intestinal specimen, perhaps due to the low concentrations observed after 7 days of DSS exposure. ${ }^{31}$ IL 4 levels are elevated and IL-5 concentrations drop after 14 days of DSS exposure, ${ }^{32}$ indicating differential effects on Th 2 activity. We found low mucosal IL-10 levels in DSS-induced colitis compared with controls, what may be a direct or indirect effect of DSS on Th2 lymphocytes. SMS and octreotide did not abolish this effect, but even further amplified to reduction of IL-10 concentration. We observed a striking decrease of IL$1 \beta$ and IL-6, after 7 days of DSS administration. This reduction was only enhanced by SMS $120 \mu \mathrm{g}$ and octreotide. In the DSS model of experimental colitis a reduced activity of mucosal macrophages as well as Th2 lymphocytes may be expected. The reduction of pro-inflammatory cytokines probably reflects a phase of mucosal regeneration in this stage of subacute colitis after 1 week of DSS exposure. Probably, the study period was too short to evaluate expected beneficial effects of SMS on the rate of post-exposure healing. Moreover, adverse effects of SMS on intestinal mucosal regeneration should be taken into account. ${ }^{33}$ The dual effect of different doses SMS may reflect different local mucosal concentrations and subsequent receptor activation. This effect is not influenced by the short half time of this instable compound, considering similar results obtained by octreotide.

In conclusion, in mice SMS or octreotide administered subcutaneously during 1 week of oral DSS exposure did not attenuate colon mucosal inflamma- tion. Low levels of mucosal IL-1 $\beta$ following DSS administration, were further decreased during high doses SMS. During administration of SMS a marked influx of PMN in colonic but not ileal mucosa was observed, also in animals not receiving DSS. These animals showed lower concentrations of mucosal IL$1 \beta$ than control animals. The meaning of this promotive role of SMS on neutrophil migration still has to be settled. SMS and octreotide amplified DSS induced decline of intestinal levels of IL-1 $\beta$, IL-6 and IL-10, suggesting further inhibition of macrophages and Th2 lymphocytes.

\section{References}

1. Stanisz AM Neuroimmunomodulation in the gastrointestinal tract. Ann NY Acad Sci 1994; 741: 64-72.

2. van Hagen PM, Krenning EP, Kwekkeboom DJ, et al. Somatostatin and the immune and haematopoetic system; a review. Eur J Clin Invest 1994; 24: 91-99.

3. Blum AR, Metwali A, Mathew RC, Cook G, Eliott D, Weinstock JV. Granuloma $\mathrm{T}$ lymphocytes in murine schistosomiasis mansoni have somatostatin receptors and respond to somatostatin with decreased IFNgamma secretion. J Immunol 1992; 149: 3621-3626.

4. Elliott DE, Weinstock JV. Granulomas in murine Schistosomiasis mansoni have a somatostatin immunoregulatory circuit. Metabolism 1996; 45 (suppl 1): 88-90.

5. Watanabe T, Kubota Y, Sawada T, Muto T. Distribution and quantification of somatostatin in inflammatory disease. Dis Colon Rectum 1992; 35: 488-494.

6. Koch TR, Carney JA, Morris VA, Go VLW. Somatostatin in the idiopathic inflammatory bowel disease. Dis Colon Rectum 1988; 31: 198-203.

7. Yamamoto $\mathrm{H}$, Morise $\mathrm{K}$, Kusugami $\mathrm{K}$, et al. Abnormal neuropeptide concentration in rectal mucosa of patients with inflammatory bowel disease. J Gastroenterol 1996; 31: 525-532.

8. Eliakim R, Karmeli F, Rachmilewitz D. Decreased somatostatin (SS) generation by colonic mucosa in active ulcerative colitis. Gastroenterology 1991; 100: A578.

9. Payer J, Huorka M, Duris I, et al. Plasma somatostatin levels in ulcerative colitis. Hepato-Gastroenterol 1994; 41: 552-553.

10. Binimelis J, Webb SM, Monés J, et al. Girculating immunoreactive somatostatin in gastrointestinal diseases. Decrease after vagotomy and enhancement in active ulcerative colitis, irritable bowel syndrome, and duodenal ulcer. Scand J Gastroenterol 1987; 22: 931-937.

11. Eliakim R, Karmeli F, Okon E, Rachmilewitz D. Octreotide effectively decreases mucosal damage in experimental colitis. Gut 1993; 34: 264-269.

12. Dziarski R Synergistic enhancement of Tcell responses and interleukin-1 receptor expression by interleukin-1 and heparin or dextran sulfate. Cell Immunol 1992; 145: 100-110.

13. Dieleman LA, Ridwan BU, Tennyson GS, Beagley KW, Bucy RP, Elson CO. Dextran sulfate sodium (DSS)-induced colitis occurs in severe combined immunodeficient (SCID) mice. Gastroenterology 1994; 107: 1643-1652.

14. Axelsson L-G, Landstrom B, Gronberg A, Bylund-Fellenius A-C. Dextran sulphate sodium (DSS) induces experimental colitis in CD4+-cell depleted, athymic and NK cell depleted SCID mice. Gut 1996; 38: A638.

15. Elson CO, Sartor RB, Tennyson GS, Riddell RH Experimental models of inflammatory bowel disease. Gastroenterology 1995; 109: 1344-1367.

16. Okayasu I, Hatakeyama S, Yamada M, Ohkusa T, InagakiY, Nakaya R. A novel method in the induction of reliable experimental acute and chronic ulcerative colitis in mice. Gastroenterology 1990; 98: 694-702.

17. Cooper HS, Murthy SN, Shah RS, Sedergran DJ. Cinicopathologic study of dex tran sulfate sodium experimental murine colitis. Lab Invest 1993; 69: $238-249$.

18. Zijlstra FJ, van Dijk JPM, Wilson JHP. Increased platelet activating factor synthesis in experimental colitis after diclofenac and 5-amino-salicylic acid. Eur J Pharmacol 1993; 249: R1-R2.

19. Domek M), Iwata F, Blackman EI, et al. Anti-neutrophil serum attenuates dextran sulfate sodium-induced colonic damage in the rat. Scand J Gastroenterol 1995; 30: 1089-1094.

20. Murthy SN, Cooper HS, Shim H, Shah RS, Ibrahim SA, Sedergran DJ. Treatment of dextran sulfate sodium-induced murine colitis by intracolonic cyclosporin. Dig Dis Sci 1993; 38: 1722-1734.

21. Björck S, Jennische E, Dahlstrom A, Ahlman H. Influence of topical rectal application of drugs on dextran sulfate-induced colitis in rats. Dig Dis $\mathrm{Sci}$ 1997; 42: 824-832. 
22. Partsch G, Matucci-Cerinic M Effect of substance P and somatostatin on migration of polymorphonuclear (PMN) cells in vitro. Inflammation 1992; 16: 539-547.

23. Wiedermann C, Reinisch N, Braunsteiner H. Stimulation of monocyte chemotaxis by human growth hormone and its deactivation by somatostatin. Blood 1993; 82: 954-960.

24. Miller SK, Martindale RG, Gao XX, Gadacz TR. The effects of octreotide on healing of small bowel anastomosis. Am Surg 1996; 62: 733-737.

25. Mulvihill SJ, Pappas TN, Fonkalsrud EW, Debas HT. The effect of somatostatin on experimental intestinal obstruction. Ann Surg 1988; 207: 169-173.

26. Benes G. Octreotide acetete (Sandostatin) to control the symptoms of Crohn's disease. Am J Gastroenterol 1993; 88: 1603.

27. Dorta G, Schnegg JF, Saraga E, Schmied PA. Treatment of gold-induced enteritis with octreotide. Lancet 1993; 342: 179.

28. Van Dijk APM, Keuskamp ZJ, Wilson JHP, Zijlstra FJ. Sequential release of cytokines, lipid mediators and nitrogen oxide in experimental colitis. Mediators Inflamm 1995; 4: 186-190.

29. Minocha A, Thomas C, Omar R. Lack of crucial role of mast cells in pathogenesis of experimental colitis in mice. Dig Dis Sci 1995; 40: $1757-1762$.
30. $\mathrm{Ni} \mathrm{J}$, Chen SF, Hollander D. Effects of dextran sulphate sodium on intestinal epithelial cells and intestinal lymphocytes. Gut 1996; 39 234-241.

31. Dieleman LA. Chapter 3.2. Chronic experimental colitis by dextran sulfate sodium (DSS) is Th1-mediated. In: Human and Experimental Studies of Acute and Chronic Intestinal Inflammation. Relevance to the Pathogenesis and Treatment of Inflammatory Bowel Disease. Amsterdam: Free University, 1995.

32. Dieleman LA, Bloemena E, van der Ende MB, Peña AS, van Rees EP. No beneficial effect of interleukin-10 in dextran sulfate sodium-induced colitis. Gastroenterology 1997; 112, Ag60.

33. Thompson JS, Nguyen B-LT, Harty RF. Somatostatin analogue inhibits intestinal regeneration. Arch Surg 1993; 128: 385-389.

ACKNOWLEDGEMENTS. This research has been sponsored by Tramedico, Weesp, The Netherlands.

\section{Received 9 March 1998;} accepted 11 March 1998 


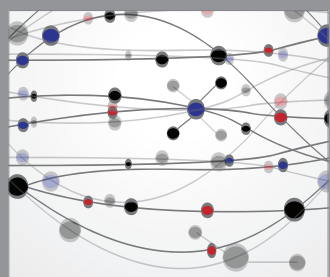

The Scientific World Journal
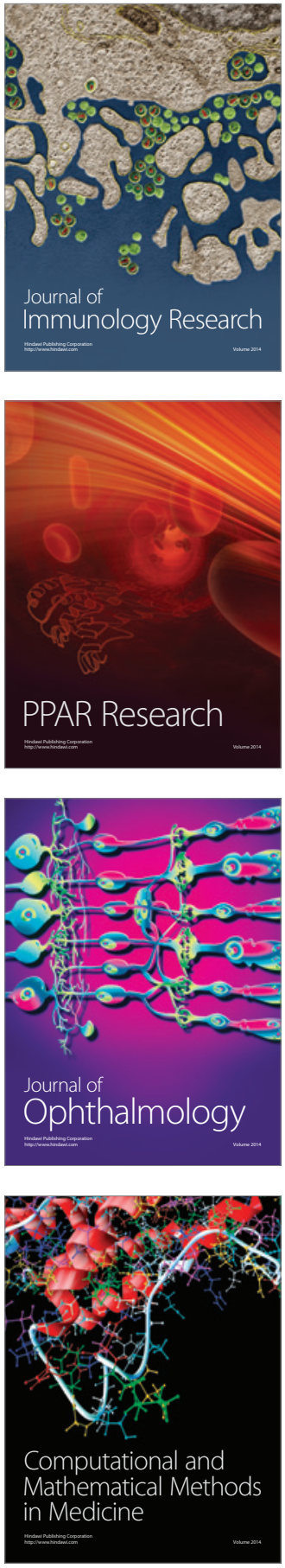

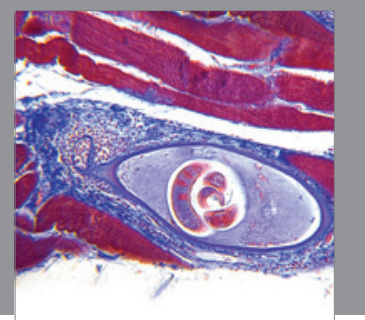

Gastroenterology

Research and Practice
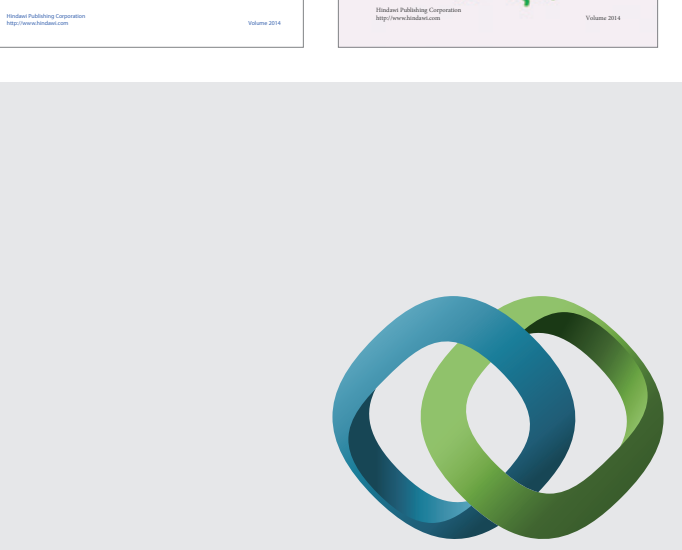

\section{Hindawi}

Submit your manuscripts at

http://www.hindawi.com
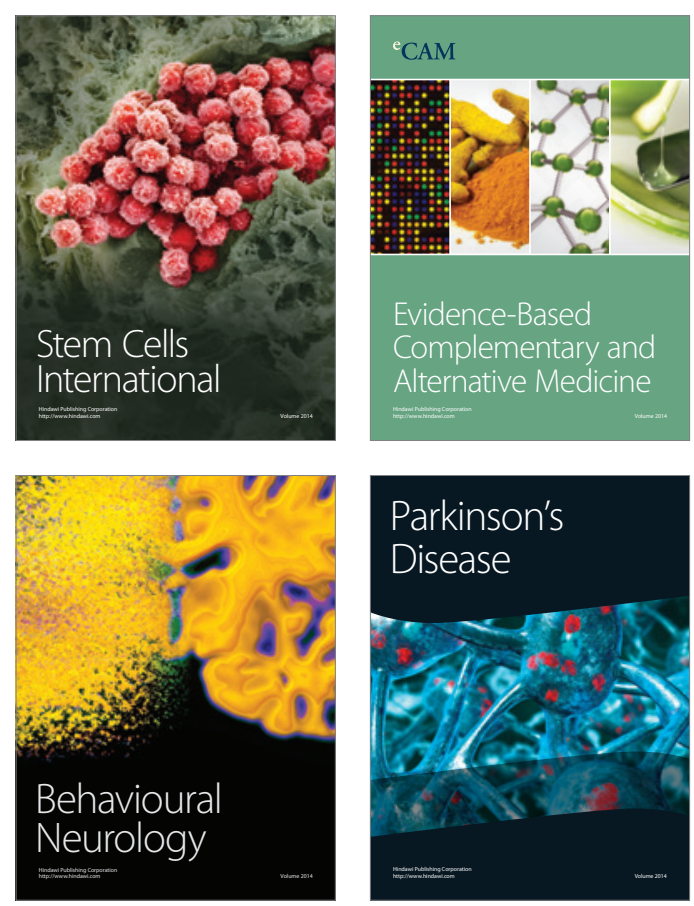

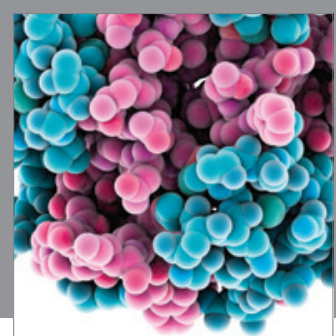

Journal of
Diabetes Research

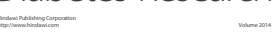

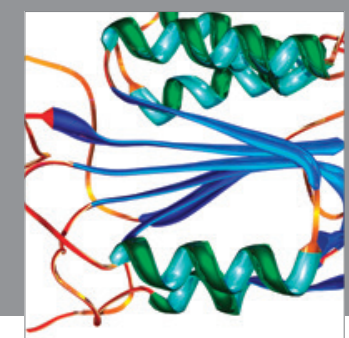

Disease Markers
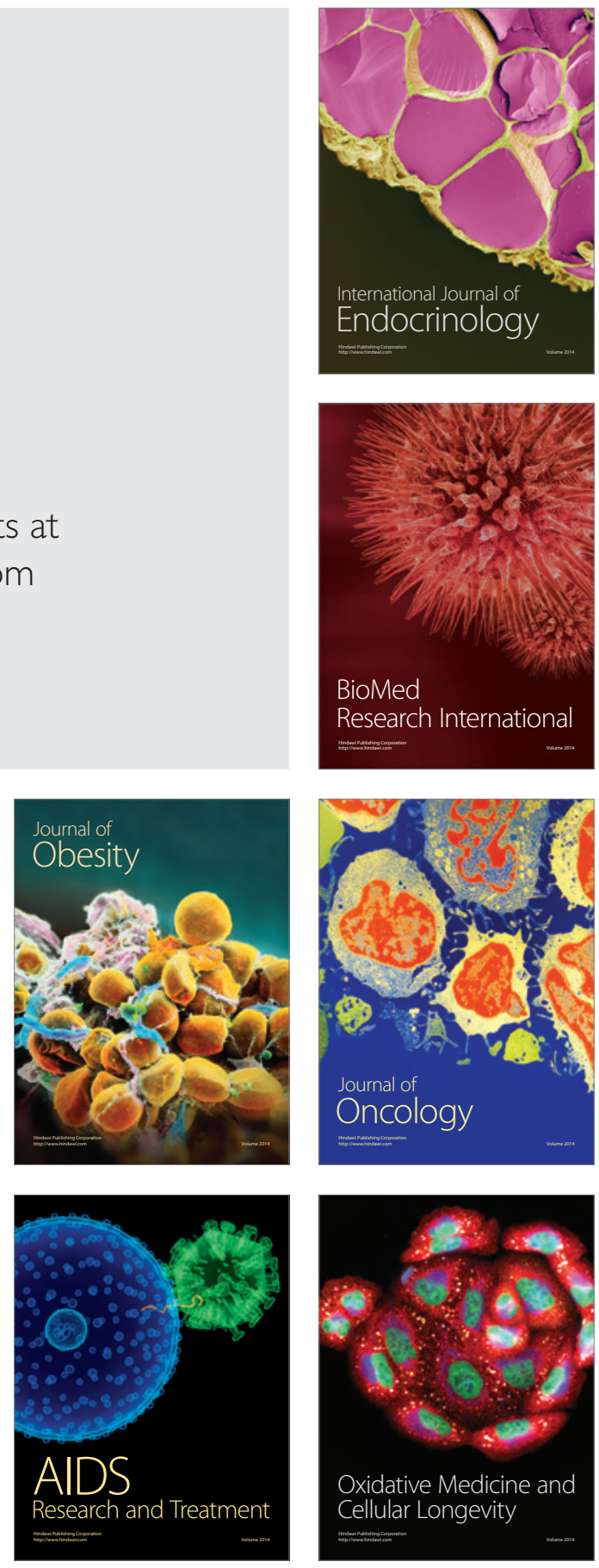